\title{
Mesa redonda sobre energía
}

El tema de la energía ocupa uno de los primeros lugares en la agenda internacional contemporánea. Las razones son variadas y van de lo económico y lo ambiental a lo político. No solo la disponibilidad y el precio de la energía son un elemento importante del bienestar de la comunidad sino que debido a que vivimos en una época que se caracteriza por la creciente participación de la sociedad civil en temas que atañen a la política pública, los índices de satisfacción o insatisfacción respecto de este elemento son muchas veces el fiel de la balanza que la mueve a manifestarse, con frecuencia en contra de proyectos o decisiones de la autoridad. En un mundo globalizado, las alzas de precio de los productos energéticos en tiempos de bonanza económica, el cambio climático que nos va afectando irrefutablemente y el control de las fuentes de energía en áreas como el Medio Oriente, elemento estratégico en las relaciones internacionales, se suman para configurar un escenario preocupante a todo nivel. Al mismo tiempo, la energía es indispensable para el crecimiento de un país y por diversos motivos muchas veces se tropieza con dificultades para ampliar la matriz energética en la medida indispensable o a un precio que no rebase sus posibilidades. Entonces, corresponde a los gobiernos velar por que la política pública contemple debidamente los problemas actuales y a largo plazo, de tal modo que incluya el abastecimiento seguro de energía en condiciones socialmente aceptables y destine los medios necesarios para la investigación y la consiguiente toma de decisiones adecuada en esta materia.

Consciente de que para los gobiernos, las empresas y la población la seguridad energética es un elemento central para la estabilidad y el desarrollo de los países y de las actividades de la población, Estudios Internacionales resolvió destinar el cuarto ejercicio de examen de los problemas que ocupan a la 
sociedad en su conjunto a analizar el tema de la energía. Para ello reunió a un grupo de destacados especialistas quienes tuvieron la oportunidad de intercambiar ideas tanto sobre la coyuntura en la materia como a mediano plazo. Para este ejercicio la revista consideró indispensable contar con la participación de representantes de los sectores público y privado, del empresariado y de analistas en materia de política energética. Desde la fecha en que tuvo lugar esta reunión de análisis el tema se ha tornado muchísimo más complejo, no solo debido a la agudización de la crisis internacional y sus probables proyecciones en nuestro país sino también por la reciente decisión de un actor del sector privado de restarse a la aprobación de un proyecto de producción de energía hidroeléctrica de gran envergadura. Este hecho nos ha puesto en la encrucijada de crear proyectos alternativos a corto plazo para satisfacer las necesidades de energía del país en circunstancias de que existen grupos de presión que despliegan esfuerzos tanto en contra de este proyecto como de sus alternativas.

La revista Estudios Internacionales se siente honrada por la buena acogida que encontró nuestra invitación entre grandes especialistas del país en el tema de la energía. A nuestro juicio, las opiniones que se dieron a conocer en esa oportunidad y que se resumen a continuación constituirán un significativo aporte para comprender los aspectos nuevos que se han sumado al tema. Es un deber ciudadano desprenderse de los prejuicios que lo rodean e impedir que se vea dominado por visiones subjetivas que entorpecen su solución.

La reseña de lo expresado en esta cuarta mesa redonda organizada por Estudios Internacionales se presenta en el orden de intervención de los participantes. A continuación, y a manera de complemento se agregan las opiniones de la señora Vivianne Blanlot, destacada especialista y ex ministra de energía y de don Rene Muga, gerente general de la asociación de generadoras, quienes no pudieron participar directamente en la reunión pero tuvieron la gentileza de hacernos llegar sus observaciones por correo electrónico. 
ANDRÉS CONCHA

(Presidente Sociedad Fomento Fabril)

No obstante que no es mi especialidad, me ha tocado vivir una experiencia muy interesante en relación con el desarrollo energético de nuestro país, específicamente con el sistema eléctrico que ha sido el que ha experimentado un mayor crecimiento en el último tiempo. Por eso, querría rescatar al respecto que estamos viviendo una realidad bastante paradojal. Resulta paradojal ya que a pesar de que estamos con una situación de mercado que refleja un nivel de precios relativamente altos en comparación con otros países en el mundo, existe una suerte de incertidumbre respecto de cuál será el desarrollo de todo este sector en el futuro.

Tenemos por una parte una fuerte demanda que se ha ido desarrollando al amparo del acelerado crecimiento que ha tenido la economía en los últimos dos años, crecimiento que probablemente continuará de manera moderada a pesar de los efectos que estamos presenciando en la economía europea y en los Estados Unidos. Esto estimulará el consumo de electricidad en el país, lo que a su vez tensionará el sistema debido a que la capacidad de organización de la oferta no ha ido asociada al crecimiento real. A ello se debe que los precios estén permanentemente flotando dentro de un rango relativamente alto para lo que ha sido la evolución histórica de estos en el mercado eléctrico chileno. Hoy día, dadas las opciones energéticas que Chile tiene, los precios debieran situarse entre 80 y 90 dólares por medida, sin embargo, lo que vemos en el mercado es que permanentemente sobrepasan los 100 dólares y en muchos casos se han elevado sobre los 150 .

Actualmente, el país cuenta con gran cantidad de proyectos cuyos estudios ya están aprobados y muchos otros que se encuentran en construcción o en curso, que claramente permiten hacer una apuesta en el sentido de que en una situación normal el desarrollo de todos estos proyectos permitiría satisfacer plenamente la demanda del mercado, a precios que hoy en día estarían en niveles que consideramos eficientes para conseguir el desarrollo del país a largo plazo. 
Entonces uno se pregunta por qué se da esta asimetría entre una demanda que aumenta de manera sostenida y a un ritmo equivalente o muy cercano al crecimiento de la economía y por otra parte, una oferta cuyo curso es relativamente más lento. Las razones son variadas, pero básicamente se trata de que las condiciones que enfrenta actualmente el mercado eléctrico chileno reflejan una serie de adversidades. Uno de los principales inconvenientes es la tecnología, en la medida que la falta de desarrollo tecnológico en los últimos años no ha permitido utilizar en su totalidad el potencial de la principal fuente de nuestra matriz energética: la hidroelectricidad. Por otra parte, nuestro país es importador neto de carbón y de gas. Aunque las importaciones del primero son generalmente al precio internacional, las del segundo dependen mucho de los contratos celebrados cuando se concretó el compromiso para construir el terminal de gas en Quintero, momento en que se fijaron condiciones de precios a largo plazo que realmente son muy superiores a los del mercado internacional. Además, vivimos un período en que por distintas razones el precio del petróleo también se ha mantenido a niveles bastante altos, lo que obviamente incide en el comportamiento de los precios tanto del carbón como del gas. Si a esta situación del mercado del carbón y de los mercados internacionales se agrega el problema de la tecnología, tenemos un escenario adverso, que en gran medida explica que los precios de la energía se hayan mantenido en niveles tan altos. A lo anterior hay que sumar otros eventos o causales de carácter transitorio, como por ejemplo el terremoto, que sorprendió al menos a dos centrales térmicas a carbón en pleno proceso de construcción y provocó perjuicios que obligaron a aplazar sustancialmente su entrada en funcionamiento, que estaba programada para el mismo 2010. La construcción de una tercera central térmica debió interrumpirse por razones judiciales, con lo cual la reanudación del proyecto se postergó prácticamente un año, de modo que no pudo contarse con el funcionamiento de una central importante que abastece el sistema central.

En consecuencia, hay varios factores que están incidiendo en el comportamiento de la oferta eléctrica en nuestro país y que mantienen los precios en niveles elevados. Ahora bien, hacia adelante existen diversos escenarios. El más probable 
sería que se aprovechara la reserva de hidroelectricidad existente en la XI región, pero la aprobación de este proyecto ha tardado más de lo esperado y ha tropezado con una fuerte oposición ciudadana que se ha manifestado de múltiples maneras, y ello de alguna forma introduce un sesgo de incertidumbre respecto de los plazos en que podrá concretarse efectivamente. En la medida en que subsistan las incógnitas en este proyecto, el desarrollo del sistema también enfrenta incertidumbres, en especial si se tiene en cuenta que requiere autorizaciones para construir un tendido de alta tensión hasta la región metropolitana de dos mil kilómetros de extensión, cuyo recorrido afectará de una u otra manera a un elevado número de propiedades.

En general, el sistema opera sobre la base de aceptar las centrales más eficientes y que, cumpliendo con las normas ambientales, pueden ofrecer sus productos a un precio menor, por lo que indudablemente la primera alternativa son las centrales que se planifica construir en la Patagonia. Sin embargo, en vista de las incertidumbres en torno a la potencial explotación de esta gran reserva energética existente en la XI región, lo lógico sería que la oferta evolucionara a partir de otro tipo de centrales, de manera tal de poder hacer frente al incremento de la demanda que seguirá registrándose en los próximos años. En ese sentido, la primera opción para sustituir el mencionado proyecto la tienen las centrales térmicas a carbón las que si bien han subido sus costos de construcción debido a que son sometidas a normas muy estrictas en cuanto a emisión de elementos contaminantes, continúan siendo la alternativa más eficiente respecto de las centrales hidroeléctricas. La utilización de gas natural, que podría ser otra alternativa dados sus bajos precios en Estados Unidos -siempre que este país pueda exportar dicho recurso-, podría fácilmente transformarse en una opción incluso más competitiva que la del carbón, pero mucho dependerá de cómo se comporten los nuevos contratos que deberán suscribirse a partir del año 2012-2013. En todo caso, como el proyecto de la central de Aysén, está en pleno desarrollo, cualquier decisión importante en materia de inversión en centrales eléctricas tiende a postergarse mientras no se resuelva el futuro de este megaproyecto. 
Como decía, nos encontramos ante una situación bastante paradojal, ya que tenemos un sistema cuyo diseño -a pesar de todas las dificultades que ha debido enfrentar a lo largo de los años- ha sido bastante exitoso: ha experimentado transformaciones relativamente importantes en respuesta a cambios de escenario y desafíos, y se encuentra hoy con un elevado número de proyectos competitivos en perspectivas de materializarse. Sin embargo, al mismo tiempo, enfrenta una incertidumbre que podría traducirse en mayores precios que los que podrían darse en el mercado interno si existiese plena certeza de que pueden materializar los plazos previstos para el desarrollo de los nuevos proyectos. Y al respecto, me parece que hay temas muy importantes relacionados con la legislación aplicable.

El escenario para el desarrollo de los proyectos eléctricos ha ido cambiando en el transcurso de las últimas décadas. En el pasado, la ejecución de un proyecto eléctrico no tenía mayor complejidad, tanto desde el punto legislativo como de las observaciones que pudiera formular la comunidad: eran otros tiempos y otros escenarios. Hoy día se van planteando numerosos conflictos relacionados con la legislación debido a que el interés en el desarrollo del sector eléctrico se entrecruza con derechos constituidos en torno a otros objetivos. Al respecto, cabe citar el caso del bosque nativo, en que Chile tiene una vasta área territorial cubierta por esta clase de bosques; o el hecho de que el país ha ratificado el Convenio 169 de la OIT, que reconoce una serie de derechos a los pueblos originarios que también se cruzan con los intereses del desarrollo eléctrico. A la vez, el sistema de otorgamiento de las concesiones eléctricas también ha variado: hay diversos tipos de autorizaciones que hay que solicitar, los trámites de obtención de las autorizaciones de impacto ambiental son más complejos y toman más tiempo satisfacer todas las necesidades. Cada vez resulta más complejo poder obtener las autorizaciones necesarias para poder llevar a cabo los proyectos en plazos relativamente razonables. La situación es claramente preocupante. A modo de ejemplo, en días pasados la empresa trasmisora Transelec, que es la principal trasmisora del sistema interconectado, informó que no postularía ni participaría en las licitaciones 
para ampliar la construcción del tendido, ya que los tiempos que solicitan las bases para entregar los proyectos eran materialmente imposibles de cumplir debido a las actuales restricciones para obtener las autorizaciones pertinentes. Las bases de las licitaciones están elaboradas de acuerdo con ciertos criterios que establece la ley y que en definitiva definen cláusulas que al parecer son incompatibles con los plazos en que las empresas tienen que cumplir los contratos. En consecuencia, la realidad para ampliar la oferta de centrales nuevas es bastante compleja.

Finalmente, diría que tenemos un gran potencial de desarrollo eléctrico, tenemos muchos proyectos, tenemos muchos inversionistas y el mercado eléctrico funciona relativamente bien, respondiendo a las señales de precio existentes, pero tenemos que atravesar por un proceso de autorización complejo, cuyos tiempos de materialización son mucho más largos que los que existían en el pasado. A mi juicio, esto explicaría por qué los precios de la energía eléctrica son tan elevados.

JORGE FERRANDO

(Gerente de Estudios, Empresas COPEC)

En realidad es un agrado comprobar que comparto gran parte del diagnóstico realizado ahora. Es muy positivo que en el sector energético de alguna forma haya consenso sobre lo que anda mal y también sobre lo que está bien. Esto es fundamental, porque hoy día Chile enfrenta grandes desafíos en materia energética: la oferta no puede marchar a la par con la demanda en circunstancias que esta continúa creciendo a un ritmo bastante acelerado; además, tenemos un problema institucional vinculado al sistema de aprobación de los proyectos que está haciendo que la energía sea muy cara en comparación con la de los países vecinos. 
Para empezar, es necesario señalar que al hablar de energía hay otros dos grandes temas que no pueden separarse: desarrollo y medio ambiente. La energía va de la mano con el desarrollo y en la actualidad los proyectos energéticos hacen frente a una posición y una participación ciudadanas mucho más comprometidas con los temas ambientales. Al mismo tiempo, la evaluación ambiental de los proyectos se ha transformado en una suerte de instrumento que la comunidad muchas veces utiliza para objetivos muy distintos de los ambientales y que responden más bien a intereses particulares en la vida y la interacción de las comunidades locales.

El vínculo existente entre energía y desarrollo está claramente presente en todos los países del mundo. Es evidente que a mayor desarrollo, mayor es el consumo de electricidad. Hay una asociación directa entre el PIB per cápita y el consumo de energía. Examinemos las estadísticas de algunos países del mundo que figuran en la página Gapminder.org, que contiene gran cantidad de información sobre muchos países y su desarrollo energético a lo largo del tiempo, presentados en forma muy ilustrativa.

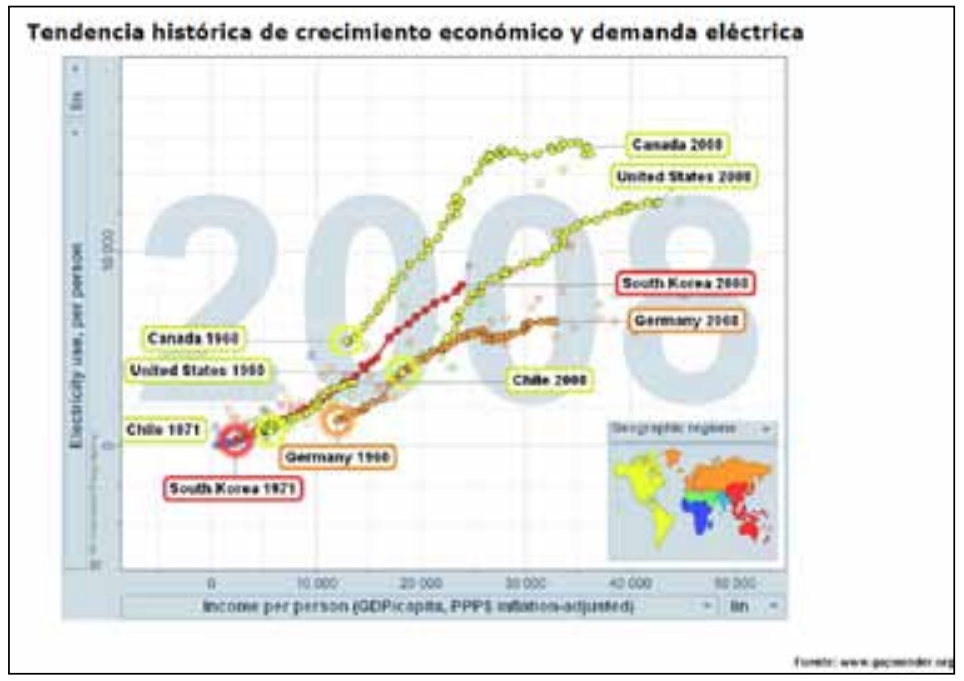

En el caso de Canadá, por ejemplo, los datos parten de los años sesenta, cuando el PIB per cápita era de aproximadamente 12 mil dólares y el consumo energético superaba los 5 mil $\mathrm{kWh}$ por habitante. Luego, a medida que fue pasando el tiempo el país se fue desarrollando y ambos fueron aumen- 
tando, primero con una pendiente muy empinada y cuando el país se transformó en una economía de servicios y empezó a aplicar medidas de eficiencia energética, la curva comenzó a aplanarse. En todos los países puede observarse la misma trayectoria. A manera de ejemplo, cabe mencionar al azar casos como los de Estados Unidos y Corea del Sur, cuyo modelo de desarrollo se asemeja al de Chile.

La historia reciente de Chile es conocida: en los dos últimos decenios la demanda de energía se ha duplicado y se prevé que en el futuro se mantendrá la tendencia. ¿Por qué? Porque el consumo de un hogar de clase media en Chile equivale a tener dos ampolletas encendidas de manera permanente. En la medida en que el país se va desarrollando, esas familias van mejorando su nivel de vida y agregando refrigeradores, microondas, etc. El desafío entonces es estar preparados para que haya energía disponible para el consumo de los hogares, independiente de cómo evolucione la demanda energética.

Para lograrlo es fundamental, por una parte, la eficiencia energética. Queremos eficiencia energética de todas maneras, porque la energía más barata y más limpia es la que no se consume. En nuestros hogares queremos consumir la menor cantidad posible de energía, queremos que la señora Juanita reemplace las ampolletas convencionales de su casa por ampolletas de ahorro energético. Pero esto no es suficiente: incluso así no alcanza. El ahorro que así se produce es mucho menor que el nuevo consumo que se agrega, el del nuevo refrigerador, o la nueva lavadora. No podemos ni queremos pedirle a la señora Juanita que no mejore su nivel de vida.

Y como no basta con la eficiencia energética, cabe preguntarse cuál es la energía que hay que agregar. La Comisión Nacional de Energía encargó un estudio del consumo energético residencial en los últimos años y si se observa lo que consumen los hogares en Chile, resulta sorprendente que el $58 \%$ consiste en leña, que tiene enorme impacto ambiental y además es muy ineficiente. Entonces, se ve que a nivel doméstico hay un enorme espacio para optimizar los recursos energéticos.

Si se examina la matriz eléctrica de nuestro país se comprueba que, de acuerdo con cifras oficiales de 2010, se compone de manera bastante equilibrada de energía hidráulica, gas natural, carbón y petróleo, con una incipiente presencia 
de energías renovables alternativas. Indudablemente todos querríamos agregarlas. Éste es el deseo que se percibe en la opinión pública. Por desgracia, al igual que lo que sucede con la eficiencia energética, las energías renovables no son suficientes para obtener toda la energía que hay que generar. Por cierto, se puede agregar biomasa y energía eólica, geotérmica y solar, pero estos sistemas por sí no darían abasto, ya que incluso en sus versiones más eficientes no aportan suficiente potencia.

De hecho, las fuentes de energía renovables representan un porcentaje muy bajo de la matriz energética, incluso en los países desarrollados donde están los proyectos más grandes de este tipo. Por ejemplo, Estados Unidos es el país en que se genera la mayor cantidad de electricidad a partir de biomasa, de energía eólica y de geotermia. Sin embargo, estas fuentes representan apenas el $1,7 \%$, el $1,3 \%$ y el $0,4 \%$ respectivamente de la generación total del país. Lo mismo sucede con la energía solar, cuyo principal productor es Alemania, pero ella aporta solo el 0,7\% de su generación total. Todos los países cuya matriz energética incluye una elevada proporción de fuentes renovables tienen enormes respaldos térmicos o nucleares. Dinamarca, que es un ejemplo al respecto ya que las energías renovables representan un $30 \%$ de su matriz, genera el $48 \%$ de su electricidad a partir de carbón, porcentaje que duplica con creces el de Chile. Por sorprendente que parezca, si comparamos directamente la cantidad de energía renovable que se genera en Dinamarca y en Chile, resulta que Chile genera más del doble que Dinamarca a partir de energías renovables limpias (24,5 mil GWh en Chile, frente a 10,9 mil GWh en Dinamarca). Entonces, hay que tener cuidado cuando se dice que Chile tiene una matriz de generación «sucia», porque las cifras revelan que esto no es así.

Adicionalmente, existen problemas derivados del tamaño y la capacidad de generación de los proyectos de energías alternativas, ya que aun si se consideran aquellos que son relativamente eficientes, es indudable que esa capacidad es bastante baja: los proyectos de biomasa generan alrededor de 40 megas, los eólicos 100, y los geotérmicos 50. Hay algunos más grandes, pero esta es más o menos su dimensión. Considerando proyectos de este tamaño y calculando cuántos se necesitan para producir los 15 mil megas que hay que agregar a la matriz en nuestro país en los próximos 10 años, es evi- 
dente que se necesitarían demasiados proyectos basados en energías renovables alternativas, y eso es impracticable. Por ejemplo, tomemos para cada tipo de energía el tamaño del proyecto más grande que hay en Chile: si fueran solo minihidro se requerirían 750 proyectos, si fueran solo geotérmicos necesitaríamos 300 proyectos relativamente grandes, si fueran solares se requerirían 250, si fueran eólicos 150 y de biomasa 375. En cambio, utilizando energías convencionales la escala varía radicalmente: en el caso del GNL estaríamos hablando de 40 proyectos; en el del carbón solo se necesitarían seis proyectos tipo Castilla que, estamos de acuerdo, es muy grande, y si fueran hidroeléctricos, como Hidroaysen bastaría con cinco. Es fácil darse cuenta de que en Chile sería simplemente imposible inaugurar una central mini-hidro cada cinco días o un proyecto solar cada dos semanas durante los próximos 10 años. No tenemos ni siquiera los equipos humanos necesarios.

Por desgracia, no solo el tamaño de los proyectos basados en energías renovables alternativas es insuficiente, sino también que tienen la desventaja de su elevado costo. Si se comparan los costos de las centrales llamadas minihídricas -que son las más competitivas entre aquellas que utilizan fuentes de energía renovables no convencionales-, se comprueba que son superiores aquellas centrales basadas en energías convencionales. La energía geotérmica e incluso la biomasa aún razonablemente, pero a partir de la energía eólica la competitividad se pierde debido a que es bastante más cara. Recordemos, eso sí, en términos comparativos que los costos de la energía son altos, y subirlos todavía más lógicamente incide en el desarrollo del país. Países como Grecia, Italia o España -que coincidentemente hoy enfrentan crisis financieras importantes- pagan cuatro veces más que en Chile por la energía obtenida de fuentes renovables no convencionales. Un país como el nuestro, que está en vías de desarrollo, no puede darse ese lujo, en especial si se considera que en los países vecinos el valor de la energía es mucho menor. Por ejemplo, si se observa el caso de la minería en Chile, se comprueba que en los últimos 10 años los costos de esta importante actividad económica se han triplicado, en gran medida debido al aumento del valor de la energía, por lo que indudablemente esta pierde competitividad. El mayor costo de las energías renovables no convencionales, incluso 
en Chile, que es un país en que estas fuentes son abundantes, es muy alto, y hay que tener presente que eso es una realidad.

Además de que la generación de energía a partir de fuentes renovables alternativas es insuficiente y cara, se ha comprobado por mucho que la gente declare que es deseable, en realidad no está dispuesta a pagar más por que ella sea limpia. A modo de ilustración, cuando Metrogas lanzó una tarifa neutra de CO2, es decir, una tarifa un $4 \%$ más alta, que permitía a los usuarios neutralizar su huella de carbono, ello sirvió para probar si la gente estaba dispuesta a pagar más por energía más limpia. De los cerca de 450 mil clientes de la empresa, un número muy reducido contrató la nueva tarifa «limpia».

En síntesis, es cierto que todos queremos energías renovables, pero el gran desafío es compatibilizar ese deseo con la realidad, es decir, que las energías alternativas son insuficientes y son menos competitivas y que lamentablemente se ha demostrado que la población no está dispuesta a incurrir en ese mayor costo.

Finalmente, otro inconveniente de estos tipos de energía es que en general no pueden aportar potencia, es decir, no hay seguridad de si estarán o no disponibles en el momento en que las necesitemos. Por ejemplo, si tenemos un sistema basado en energía eólica, ¿de dónde se obtiene la energía cuando no sopla viento? Y si es solar, ¿qué hacemos en la noche para encender la luz? ¿cuando no llueve, si tenemos mini-hidro?. El problema de estas energías intermitentes es que requieren un respaldo que pueda garantizar su disponibilidad, lo que en definitiva significa que igual debemos construir centrales térmicas. Y eso nos plantea un nuevo dilema: si de todas formas tenemos que construir las térmicas y ya incurrimos en ese costo, ¿tiene sentido seguir gastando aún más solo para usar menos las centrales que ya tenemos?. El problema de la intermitencia le resta aún más competitividad a las fuentes alternativas.

Por otra parte, si se comparara la posición de Chile en el contexto internacional en términos de energías renovables, a primera vista parece que nuestro país no está muy bien posicionado en relación con países como Dinamarca, cuya matriz incluye un $30 \%$ de energía basada en fuentes renovables no convencionales, como se ilustra en el siguiente gráfico. 


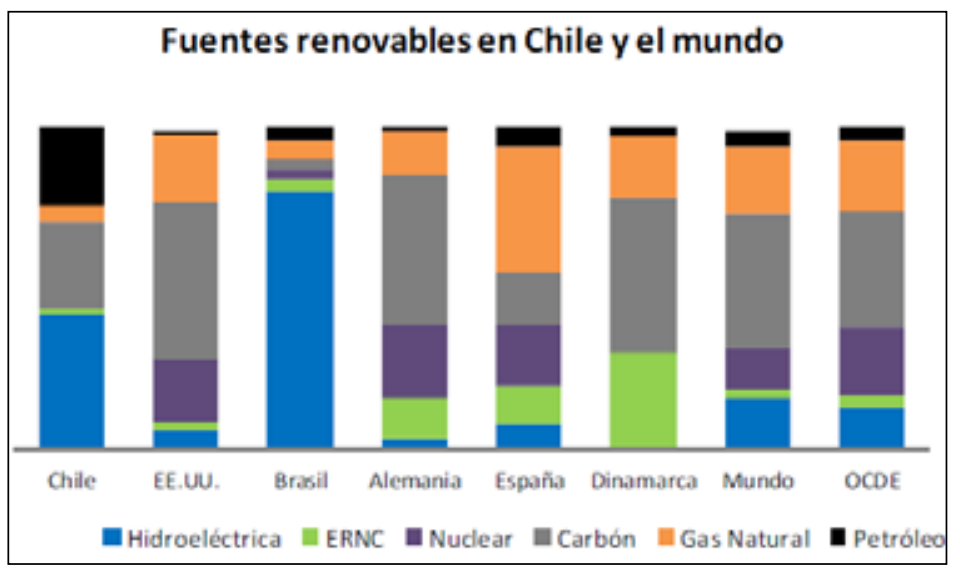

Esta es la imagen de Chile que percibe la opinión pública y que se resume en la idea de que "Chile es un país con una matriz poco renovable». Pero esa idea esconde una falacia. Para aclararlo conviene simplificar un poco el análisis agrupando las fuentes térmicas convencionales (nuclear, carbón, gas natural y petróleo), lo cual se obtiene en el siguiente gráfico, que es lo mismo que el anterior pero agrupando las fuentes térmicas convencionales.

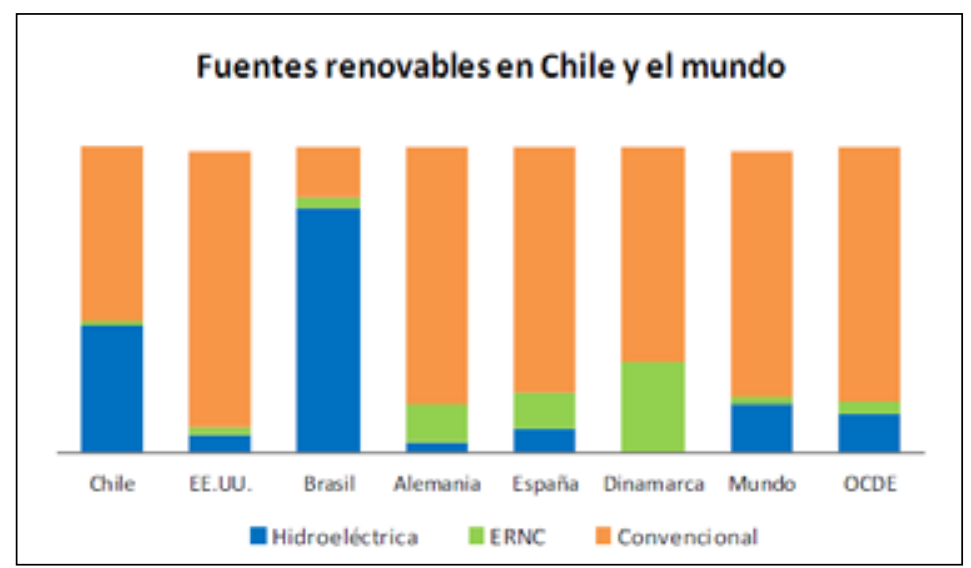

Resulta quizás sorprendente comprobar que en Chile la generación térmica convencional representa un porcentaje mucho menor, no solo respecto del resto del mundo y los países de la OCDE, sino que incluso si se compara con los países ícono de las energías renovables. Solo en el caso de Brasil la 
comparación resulta desfavorable para Chile, debido a la gran riqueza hídrica que aprovecha.

También se percibe que en Chile preocupa que se hayan construido y se sigan planificando centrales a carbón. Eso también es un mito. De hecho, solo en Estados Unidos se construyen centrales térmicas a carbón por una capacidad total que supera la capacidad total instalada en Chile actualmente de todas las formas de energía, no solo térmica. Para qué hablar de China e India. De hecho, en todos los escenarios de proyección de la Agencia Internacional de la Energía se contempla un aumento de la generación a carbón a nivel mundial.

Por otra parte, la naturaleza de nuestro país tiene un fuerte componente de energía hidroeléctrica "que también es renovable y limpia-, y ello también nos favorece en la comparación internacional. Para simplificar aún más el análisis, si en el mismo gráfico anterior agrupamos en una sola categoría todas las energías renovables limpias, es decir hidroelectricidad y ERNC, obtenemos lo siguiente:

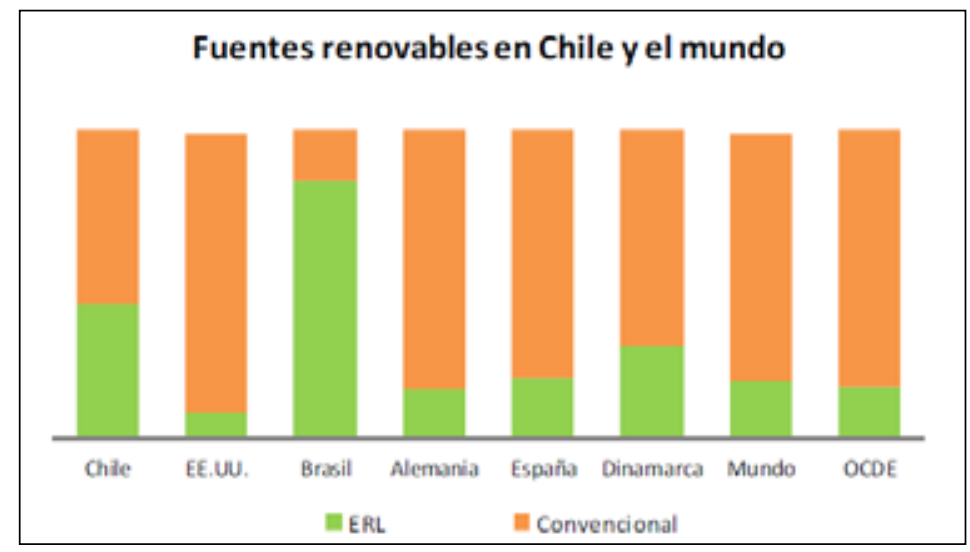

Contrariamente a lo que percibe la opinión pública y en el debate energético, la realidad es que en Chile la energía es muy renovable y limpia. En nuestro país las energías renovables representan hoy alrededor de un $40 \%$ de la matriz, mientras que en Europa solo se aproximan al $15 \%$. Hoy cumplimos ampliamente la meta que Europa se impuso para el año 2020. Por lo tanto, en materia de energía basada en fuentes renovables, estamos bastante bien parados a nivel mundial, solo que no lo sabemos. 
Además, nuestra normativa en materia de calidad del aire es más estricta que la europea y las nuevas normas aplicables a las emisiones de las termoeléctricas son más exigentes que las de la Unión Europea y que las recomendadas por el Banco Mundial. Esto quiere decir que no obstante que en algunos países de ese continente la reglamentación es más estricta que en Chile, los proyectos que cumplen las nuevas normas chilenas podrían perfectamente construirse en el centro de las grandes ciudades de Europa. Sin embargo, pese a que los proyectos presentados últimamente cumplen con estas normas, en nuestro país enfrentan el rechazo y la oposición ciudadanas, por lo que cabe preguntarse qué sentido tiene aplicar normas tan estrictas si ni siquiera aplicándolas se pueden llevar a cabo los proyectos.

Para concluir, puede decirse que el crecimiento de Chile requiere más energía. En consecuencia no se trata de elegir: hay que utilizar todas las fuentes disponibles y sumarlas, porque necesitamos toda la energía que puede producirse. De esta manera tendremos una matriz energética más diversificada, con un suministro seguro de energía barata y sustentable. Con el tiempo y en la medida en que la tecnología permita ir otorgándole mayor competitividad a las energías alternativas y superar los problemas que he mencionado, indudablemente irán ocupando un mayor lugar en la matriz. Sin embargo, mientras tanto, no hay que insistir demasiado en incorporarlas, ya que a nivel mundial Chile está bastante bien en materia de energías renovables. En cuanto a la protección del medio ambiente, si la normativa aplicada es una de las más exigentes del mundo, debería bastar con cumplirla. Lamentablemente esto no está sucediendo y ello dificulta nuestro desarrollo. 


\begin{abstract}
Alejandro Jadresic
(Decano Facultad de Ingeniería y Ciencias,

Universidad Adolfo Ibañez)
\end{abstract}

Lo dicho hasta ahora revela claramente que el sector energético plantea un problema y que el problema es difícil de resolver. Además de los aspectos propiamente técnicos, como podrían ser las dificultades en temas relacionados con la seguridad o las emisiones de las centrales, el gran desafío que hoy enfrenta el sector tiene que ver con la manera de conciliar el desarrollo de proyectos energéticos con otros objetivos e intereses de carácter regional. Me refiero a la dicotomía que a menudo se da entre el desarrollo energético y el desarrollo local, por ejemplo, en ámbitos como el turismo. Ahora bien, aunque esto es complejo, a mi juicio hay un tema que es aún más difícil de resolver, que es el problema político. En efecto, a nivel político y a nivel de la ciudadanía no hay consenso suficiente sobre cuál es el modelo de desarrollo energético que queremos para el futuro, y ello ha provocado una suerte de estancamiento de la evolución del sector. Obviamente, este es el principal problema por resolver y es lo que hoy nos tiene discutiendo y formando comisiones para analizar argumentos, contrastar ideas y, finalmente, intentar llegar a ciertos consensos.

Para lograr acuerdos se constituyó, por ejemplo, la Comisión Asesora para el Desarrollo Eléctrico (CADE) en la que me correspondió participar. Lo interesante de experiencias como esta es que pese a que la Comisión está integrada por especialistas de distintas áreas, perfiles y sensibilidades, más centradas en lo ambiental o en lo económico, logramos llegar a un nivel de consenso en aspectos bastantes más específicos de lo que yo hubiese esperado. De hecho, al comienzo pensé que nos pondríamos de acuerdo en ciertos lineamientos estratégicos generales sobre nuestras políticas, pero para mi sorpresa surgió una propuesta que tiene sustancia y posibilidades reales de materializarse. Además de que se propusieron cambios importantes que indudablemente no pueden hacerse en un solo gobierno porque son de mucho mayor plazo, la Comisión hizo un valioso esfuerzo por cuantificar y anali- 
zar seriamente cuáles serían las consecuencias y los costos de las distintas políticas que podrían aplicarse. Es decir, se propusieron distintas opciones de modelo de desarrollo eléctrico, cuantificando los costos, los beneficios, las tarifas y las emisiones de cada una. Gracias a esta base de comparación, actualmente se puede calcular con relativa precisión cuáles serían las implicaciones que tendría para la sociedad chilena adoptar distintas decisiones en la materia.

Entre las conclusiones a que llegó la CADE cabe mencionar primero la importancia del recurso hidroeléctrico, que ya se está explotando en Chile pero que aún puede desarrollarse bastante más. A ello hay que agregar que si bien la hidroelectricidad enfrenta dificultades políticas, puesto que no existe el consenso requerido para su explotación, desde el punto de vista técnico presenta bastantes beneficios en aspectos tanto económicos como ambientales. La energía hidráulica, particularmente el proyecto Hidroaysén, tiene grandes ventajas, entre otras razones no está sujeto a la realidad climática que estamos enfrentando en la zona central del país, ya que la central se alimentaría de hielos milenarios que esperamos sigan estando allí por bastante tiempo. Por otra parte, la energía térmica continuará siendo importante y necesaria, de modo que a lo largo del tiempo la generación a carbón conservará importancia. También existe la opción del gas natural, razón por la cual uno de los temas que se examinaron en la CADE fue el acceso a las terminales de GNL. En cuanto a las energías renovables no convencionales, la Comisión fue bastante optimista respecto de su competitividad a mediano plazo. Actualmente, la ley contempla llegar a 2020 - de manera referencial, no obligatoria - con una matriz que incluya un $8 \%$ de esta clase de energías. A nuestro juicio, es factible que en 2024 este porcentaje se sitúe entre un 12 y un $20 \%$. Ahora bien, es preciso ser cautelosos respecto de la forma de poner en práctica estos sistemas. Por ejemplo, es posible que el costo de promover el uso de energías renovables mediante licitaciones de tecnología sería muy alto para el país. Hay otras maneras más eficientes de hacerlo, como proponer formas de financiamiento que faciliten la entrada de nuevos inversionistas que dispongan de tecnología para desarrollar este tipo de proyectos.

Otro tema que conviene tener presente son ciertas características del mercado energético nacional, que por cierto influyen en 
las elevadas tarifas actuales. Desde luego, la alta concentración del sector es un hecho evidente, pero más allá de ello las empresas que operan en él carecen de presión suficiente para desarrollar proyectos, e incluso para que se resuelva o acelere la ejecución de los que ya se encuentran en marcha. De hecho, una de las conclusiones del modelo propuesto por la Comisión fue que una de las variables que tiene más impacto en las tarifas es el atraso en la ejecución de los proyectos. Además de que las dificultades con que se tropieza para llevar a cabo o concretar proyectos es un hecho objetivo, si se atrasa su ejecución las tarifas altas se mantienen. En realidad, esto beneficia a los empresarios ya instalados, puesto que los que en definitiva asumen ese costo son los consumidores, en especial el consumidor industrial.

Fuera del valor que puedan tener iniciativas como la CADE o el trabajo de la Comisión Técnica Parlamentaria convocada para discutir el tema, no basta con ponerse de acuerdo sobre algunos de sus aspectos, porque el desafío es mucho mayor. Para resolver con éxito los problemas que hoy enfrenta el sector energético se requiere un consenso general a nivel político y social. Al respecto, soy bastante pesimista y creo que este tema nos seguirá acompañando por varios años. En la medida en que el proceso político se siga guiando por el people meter, en vez de que sean los niveles políticos quienes formen las opiniones, informen a la ciudadanía y tomen medidas a mayor plazo, será muy difícil llegar a acuerdos que permitan soluciones óptimas. Por otra parte, es fundamental que las empresas tomen conciencia de su responsabilidad a la hora de generar consensos en relación con sus proyectos. Hasta ahora estaban acostumbradas a que fuera el gobierno quien hiciera el trabajo sucio o incómodo, ello ya no es así: los empresarios deben adaptarse a que para lograr legitimidad, actualmente los proyectos de ingeniería no pueden hacerse de manera aislada sino que deben complementarse e integrarse con políticas de desarrollo social y económico.

En cuanto a las políticas energéticas actuales, la semana pasada tuvimos oportunidad de escuchar un planteamiento del Presidente de la República. Aunque no lo comparto plenamente, como integrante de la CADE tuve la satisfacción de constatar que dicho planteamiento incorporó muchos de los temas que nosotros formulamos. El desafío que enfrenta ahora el ministro de energía es convertir esa visión estratégica en un 
plan de acciones concretas. La tarea no será fácil, en especial si se considera que al gobierno solo le quedan un par de años, de tal modo que no es mucho lo que podrá hacer más allá de priorizar dos o tres temas específicos. Además, hay que tener presente que no cuenta con el apoyo legislativo necesario. En la práctica no se dan las mayorías requeridas para lograr que se aprueben este tipo de iniciativas y con elecciones en un futuro cercano en el Congreso difícilmente podrá avanzarse mucho. En lo que sí se puede avanzar es en la discusión pública y en llegar a ciertos acuerdos, que indudablemente ayudarán mucho. Es cierto que lo ideal sería reformar la legislación y las normas, pero incluso con el sistema imperfecto que tenemos actualmente se puede hacer mucho, se pueden resolver los problemas de otra manera. Naturalmente, en este caso también se requiere la voluntad del gobierno y de la disposición de los sectores políticos y empresariales. Una cosa es el ideal de desarrollo eléctrico a que aspiramos y otra lo que efectivamente se puede conseguir. Si logramos un modelo que funcione, que aunque no sea óptimo sea legítimo, que sea apoyado por la gente y con el que que también se beneficien las localidades en que se encuentran los recursos, hay que contentarse con eso. Si continúa el estancamiento actual, estamos perdidos.

\section{NICOLA BORREGAARD}

(Gerente de energía y cambio climático, Fundación Chile)

Cuando se habla de política energética surgen fundamentalmente tres ejes relevantes. Ellos figuran en las políticas tanto a nivel nacional como internacional, ya que los tienen presentes todos los países a la hora de plantear sus estrategias de desarrollo energético. En ese sentido, cualquier política apunta resolver primero la seguridad de suministro, luego, a que el precio de la energía sea accesible; y por último, a que la energía de que dispone sea limpia. 
Pero no basta solo con tener en cuenta estos tres elementos: es fundamental definir con claridad sus estándares, vale decir, hay que establecer qué niveles de seguridad, de costos y de sustentabilidad ambiental queremos. A partir de estos objetivos el país tiene que tomar decisiones. En el caso particular de Chile y de otros países en que hay gran desigualdad socio-económica se agrega otra variable, que es la justicia social. Al amparo de las discusiones sobre la evaluación ambiental ha surgido con fuerza una segunda reivindicación de carácter social. Por lo tanto, ante la fuerza que han adquirido los movimientos ciudadanos en el último tiempo y de sus exigencias en relación con una mayor equidad estructural del sistema, es indudable que a la hora de plantear una política energética en nuestro país es necesario definir además el tema de la justicia social, vale decir, cuán justo queremos que sea el acceso a la energía, y la distribución de beneficios y costos en la generación energética. Las problemáticas y desafíos que enfrenta el sistema energético, especialmente a nivel de la legitimación ciudadana de los proyectos, no pueden resolverse solo con una mejor legislación ambiental: necesariamente hay que tomar en cuenta el componente social.

Si se examina la actual matriz energética del país se comprueba que se compone de un $36 \%$ de hidroelectricidad, de un $62 \%$ de energía térmica y de un mero $2 \%$ de energías renovables no convencionales, pero prácticamente no se habla de eficiencia energética. Frente a estas cifras, la hoja de ruta hasta 2020 propuesta por el Presidente Piñera contempla un $12 \%$ de eficiencia energética, así como a nivel orientativo, el aumento a $20 \%$ del uso de fuentes de energía renovable no convencionales y que la energía hidráulica disponible represente un $50 \%$ de las necesidades. Al mismo tiempo, esto llevaría implícito, una reducción drástica a $18 \%$ el uso de energía térmica. A lo anterior habría que agregar los ajustes regulatorios ambientales, sociales y de eficiencia económica que hagan posible alcanzar el óptimo social. Por su parte, las propuestas de la CADE para el Plan 2010-2020 contemplan un $12 \%$ de eficiencia energética y la inclusión en la matriz de un $15 \%$ de energías renovables no convencionales en 2024.

Al tener en cuenta las características de nuestra matriz energética y su proyección en el tiempo a nivel de planificación, es evidente que este no es el momento para decidir 
quién gana a nivel país. No se trata de establecer si gana Sara Larraín con su propuesta basada en la utilización de energías renovables no convencionales, o si ganan Colbún con Endesa para la construcción de Hydroaysen. Antes de tomar decisiones es fundamental avanzar efectivamente en los ajustes necesarios para aplicar una política pública adecuada, que permita llegar a buenos resultados en el sector, y esto hay que hacerlo relativamente rápido. A mi juicio, en el contexto actual, aplicar una política energética valiente no consiste en imponer el uso de una u otra fuente sino en crear un marco de política pública adecuado para poder desarrollar aquellas fuentes de energía que producen mayor bienestar social. Ello exige entre otras cosas avanzar con urgencia en la regulación ambiental y territorial, en especial en lo que se refiere a las plantas termoeléctricas e hidroeléctricas, realizar ajustes al marco regulatorio e institucional aplicable al sector eléctrico y crear nuevos canales formales de participación democrática.

Lo que queremos hacer es llegar a un óptimo social y para ello tenemos que utilizar distintos mecanismos. Primero hay que hacer ajustes para que los intereses de la sociedad se canalicen más eficazmente, pero al mismo tiempo fomentar objetivos de bien público promoviendo ciertos temas desde una perspectiva amplia, es decir, entendiendo que no todo se puede analizar desde un punto de vista exclusivamente económico. En ese sentido, corresponde al Estado proteger y fomentar objetivos de bien público y promover la eficiencia energética. El Estado debe hacer que el sector funcione eficientemente, a la par que ir mitigando los costos de la implementación de ciertos sistemas, o eliminando las barreras para el desarrollo de nuevas alternativas. Es cierto que en definitiva quien decide es el mercado, con mayor razón en las condiciones actuales, pero claramente el Estado tiene una función muy relevante.

El logro del óptimo social obliga a trabajar diversos temas. Por ejemplo, es necesario resolver el tema de la concentración del mercado, ya que un $75 \%$ de la potencia instalada y el $90 \%$ de los contratos están en manos de 3 grupos económicos. Todos tenemos conciencia de que el aumento de los precios de la energía en los últimos años no ha dependido tan solo del incremento de los costos a nivel de mercado: indudablemente se requieren ciertos ajustes a nivel de las reglas de competencia. Por otra parte, está 


\begin{tabular}{|c|c|c|c|c|c|}
\hline 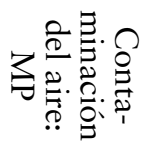 & 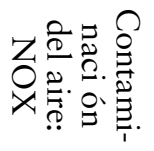 & 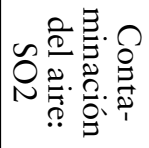 & 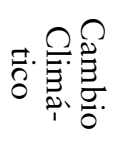 & 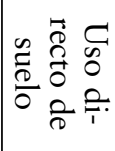 & $\begin{array}{l}\Xi_{\overparen{D}}^{\Xi} \\
\stackrel{0}{0} \\
0\end{array}$ \\
\hline ত্রু & 四 & 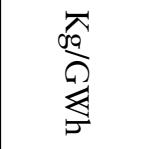 & $\begin{array}{l}\overparen{\pi} \\
30 \\
30 \\
0 \\
0\end{array}$ & $\stackrel{\frac{T}{2}}{2}$ & 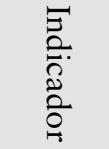 \\
\hline 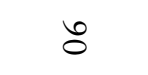 & $\stackrel{\sigma}{\sigma}$ & $\stackrel{\vartheta}{\sigma}$ & ఠ & $\stackrel{w}{8}$ & 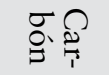 \\
\hline$\breve{o}$ & $\begin{array}{l}w \\
\circ\end{array}$ & $\tilde{\sigma}$ & ฟै & $\overrightarrow{0}$ & 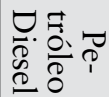 \\
\hline$\widetilde{N}$ & $\stackrel{1}{\circ}$ & $\overrightarrow{0}$ & $\begin{array}{l}\tilde{N}_{\omega} \\
\text { un } \\
\mathcal{u}_{1}\end{array}$ & $\overrightarrow{0}$ & 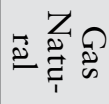 \\
\hline 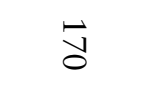 & 巨 & $\stackrel{\infty}{\circ}$ & $\underset{w}{N}$ & 巨 & 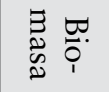 \\
\hline 0 & 0 & 0 & $\stackrel{V}{N}$ & $\frac{\tilde{A}}{\omega}$ & 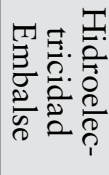 \\
\hline 0 & 0 & 0 & $\stackrel{+}{i}$ & 8 & 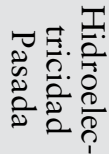 \\
\hline 0 & 0 & 0 & $\vec{\omega}$ & ᄋ̊ & $2 \stackrel{\frac{\pi}{0}}{7}$ \\
\hline 0 & 0 & 0 & $\begin{array}{l}+\infty \\
\infty \\
\infty\end{array}$ & $\stackrel{\overrightarrow{8}}{8}$ & $\frac{\mathscr{0}}{ٍ ֶ}$ \\
\hline 0 & 0 & 0 & $\vec{\omega}$ & 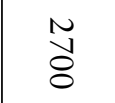 & 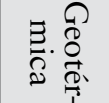 \\
\hline 0 & 0 & 0 & 6 & $\stackrel{v}{a}$ & 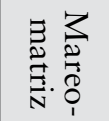 \\
\hline 0 & 0 & 0 & $v_{v}^{w}$ & ন & 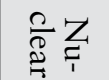 \\
\hline
\end{tabular}


el tema del impacto ambiental, y más allá de mayor regulación también se requiere de mayor información al respecto. Por primera vez, la Plataforma de Escenarios Energéticos 2030 elaboró una tabla comparativa entre las distintas fuentes energéticas de distintos aspectos ambientales. Este análisis permite cuantificar el impacto de las distintas fuentes de energía, aunque es importante tener en cuenta que esas cifras son solo indicativas a nivel general sobre el impacto potencial y a nivel de impacto real esto puede variar significativamente. El impacto de un determinado proyecto puede mitigarse en proporción importante, ya que variables como la tecnología o el adecuado emplazamiento espacial o territorial de un proyecto tienen mucho que ver con su nivel de impacto. Además, aún no se consideraron en este análisis aspectos de orden cualitativo como la biodiversidad, el consumo de agua, el paisaje, el ruido y los desechos, que son difícilmente cuantificables. Además, un tercer tema que hay que estudiar es la agudización de los conflictos sociales en un contexto de creciente empoderamiento de la sociedad civil. Prueba de ello son las manifestaciones públicas de rechazo a la instalación de centrales que han tenido lugar en distintos puntos del país invocando sus efectos nocivos para el medio ambiente. Por último, debe estudiarse la creciente complejidad del tema del uso del suelo, las restricciones existentes en cuanto a distintas formas de definición de destino del uso de suelo, la ubicación de las áreas protegidas del Sistema de Áreas Silvestres Protegidas por el Estado (SNASPE) y los derechos de agua no consuntivos, ya que las solicitudes de derechos de uso de agua se traslapan con las áreas protegidas. El predominio del código de aguas sobre las áreas protegidas está generando graves problemas; además, no existe claridad respecto de si entregar o no las solicitudes, ni cómo dirimir esos temas. En definitiva, lo que hay que tener presente es que si se apunta a alcanzar un óptimo social es necesario considerar numerosos aspectos a nivel de la validación de centrales. Esto exige que las empresas tengan un nivel de expertise que antes no se requería.

En síntesis, puede decirse que los temas de la sustentabilidad ambiental y social penetran prácticamente todos los aspectos de la discusión energética. Todavía subsiste una dicotomía entre las exigencias y el nivel teórico de conciencia medioambiental y el comportamiento del mercado en la práctica. Así, a una ciudadanía empoderada y cada vez más 
consciente en relación con estas temáticas se contrapone el aumento, en Chile así como en otros países a nivel mundial, del valor de las emisiones de CO2 registrado entre 1990 y el 2007.

(tCO2e per cápita)

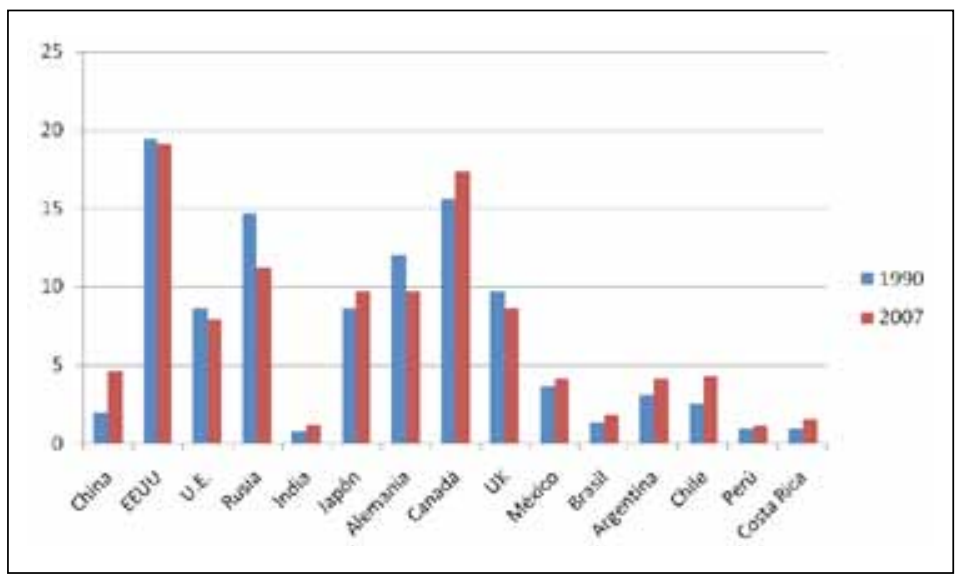

Fuente: IEA, "CO Emissions from Fuel Combustion", 2009

Es indudable que la importancia de la huella de carbono en relación con la producción pasa a ser un aspecto importante que debe considerarse en forma apremiante. Si bien la disminución de las emisiones y del impacto a la hora de generar productos es una exigencia que pesa de manera creciente, especialmente sobre el sector exportador, lo está haciendo también para la industria orientada al mercado interno, cercana al consumidor final. Por esta razón, el análisis de medidas de internalización de esta externalidad negativa global debe formar parte de la estrategia a aplicar en el futuro en el sector. Los ajustes que se proponen distan de ser marginales y comprenden el diálogo sobre la política energética y la coordinación por el sector público de la elaboración de líneas de base ambientales, fortaleciendo la participación ciudadana y la inclusión del tema energético en la elaboración de los planes de desarrollo territorial. Además de lo anterior, convendría analizar el caso de la hidroelectricidad en el sur del país, así como el pago de una patente por los derechos de uso de agua no consuntivos. En lo que respecta al ordenamiento territorial, en el caso de las termoeléctricas se propone trabajar con el concepto de áreas aptas o recomendadas, e introducir una 
nueva figura de protección de cuencas para las hidroeléctricas y aplicar un sistema de compensaciones locales que comprenda el pago de un porcentaje de las utilidades.

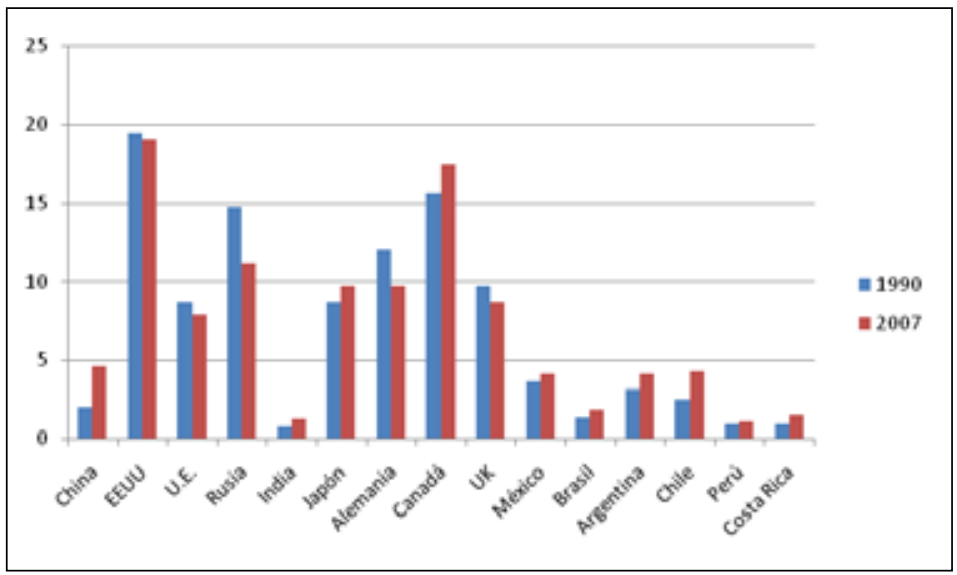

Las propuestas anteriores se complementarían con un Plan de Acción de Eficiencia Energética que introduzca cambios regulatorios importantes y cuyas metas sean mensurables y verificables. Finalmente, soy partidaria de crear la figura del mercado minorista y la aplicación de una serie de instrumentos que derriban las barreras que enfrenta actualmente el uso de las energías renovables no convencionales.

RODRIGO GARCÍA PALMA

(Gerente Técnico, Centro de Energía Renovables, (CORFO)

Las fuentes de energía renovables han estado en el centro de las discusiones, no solo debido a los crecientes temores respecto de la disponibilidad de fuentes tradicionales sino también a su alto costo. Al referirme a ellas lo haré desde la perspectiva del Centro de Energía Renovable de la CORFO -cuyo directorio 
está regido por el Ministro de Energía-, que tiene por función entregar insumos para la creación de políticas a largo plazo. En este momento, los objetivos a que apunta el Centro se relacionan sobre todo con la producción y fomento del uso de estas fuentes, el estímulo al emprendimiento, y la facilitación del desarrollo de dicha cartera, independiente del nivel de madurez tecnológico disponible actualmente en el país. Antes de referirme específicamente a las iniciativas y al análisis que hace el Centro como institución en relación con la utilización de este tipo de energías, querría referirme a la política general del gobierno al respecto y al potencial desarrollo de los distintos tipos de energía renovables disponibles en el país.

En lo que se refiere a la política energética del gobierno, cabe señalar que sus tres ejes fundamentales son promover la producción de energía a precios competitivos, asegurar el abastecimiento energético del país, e implementar una matriz ambientalmente sostenible. Debido a la potencial importancia de las energías renovables no convencionales, se ha desarrollado un marco normativo favorable para su incorporación en la matriz eléctrica. La Ley 20.257 establece que en 2014 las empresas que comercialicen energía en sistemas mayores deben acreditar la inclusión de un $5 \%$ de esta clase de energías, porcentaje que deberá llegar a 10\% en 2024. Desde luego, en materia de generación la llamada Ley Corta crea ventajas competitivas para los proyectos energéticos de capacidad inferior a $20 \mathrm{MW}$, favoreciendo así el desarrollo de las llamadas minihidráulicas. Actualmente hay 34 centrales de esta naturaleza en operación y 41 proyectos nuevos, 25 de los cuales han sido declarados ambientalmente sostenibles.

Considerando que en Chile el potencial de energía eólica se aproxima a los 4 mil MW y pese a que en los últimos años han aumentado las inversiones en la generación de esta clase de energía, por ahora las cifras alcanzadas son relativamente menores. A medida que se perfeccione la tecnología y se avance en el desarrollo de los proyectos se prevé un incremento de su aporte a la matriz energética. Actualmente, el Sistema de Evaluación del Impacto Ambiental registra 21 parques eólicos con Resolución de Calificación Ambiental (RCA) aprobada, que generan una potencia cercana a 2 mil MW. Los proyectos aún no clasificados generarían más de mil MW adicionales. 
En consecuencia, hay que enfrentar grandes desafíos, entre los que cabe mencionar el mejoramiento de la integración de proyectos eólicos al sistema eléctrico del país, la estimación precisa del recurso disponible y el desarrollo de capacidad técnica local especializada en el diseño, construcción, operación y mantenimiento de proyectos eólicos.

Pese a que en Chile, especialmente en el norte del país, hay un enorme potencial de radiación solar, el elevado costo de la tecnología de generación ha impedido hasta ahora que haya proyectos de energía solar conectados al sistema eléctrico. Solo se han desarrollado pequeñas soluciones fotovoltaicas y colectores solares para agua caliente sanitaria. Con todo, el Sistema de Evaluación de Impacto Ambiental (SEIA), registra siete proyectos de generación solar con RCA aprobada y hay otros cuatro en curso de evaluación ambiental. Cabe señalar que actualmente se estudia un subsidio parcial para la materialización de una pequeña granja solar para el suministro de energía eléctrica a San Pedro de Atacama, en la II Región, que se utilizaría como experiencia piloto en el desarrollo a gran escala de la energía solar.

Otras fuentes de energía renovables son la geotermia y la bioenergía. La primera apunta a aprovechar el calor existente en las capas interiores de la corteza terrestre para convertirlo en electricidad o calor aprovechable. Chile se ubica en una zona de alta actividad volcánica (hay cerca de 2900 volcanes, 80 de ellos en actividad permanente, mientras que aproximadamente 270 tienen fuentes termales) pero no se han concretado proyectos de generación eléctrica no solo por el alto costo de exploración e inversión sino por la baja competitividad frente a las fuentes de generación convencionales. La crisis por la que atraviesa el sector energético ha dado mayor impulso a la exploración geotérmica iniciada por el proyecto de perforaciones de la CORFO de 1968, con la cooperación técnica de Italia y las Naciones Unidas. El primer proceso masivo de licitación de concesiones geotérmicas, de 2009, adjudicó 16 de los 20 sitios licitados. Uno de los desafíos importantes que enfrenta el desarrollo del sector es el impulso de la industria auxiliar local para prestar servicios de manera rápida, confiable y a bajo costo. 
Finalmente, en cuanto a la producción de bionergía, cabe mencionar que es una alternativa muy atractiva para Chile debido a la disponibilidad de diversas fuentes de biomasa, al hecho de que existen tecnologías en etapa comercial y a la variedad de usos que puede darse a los productos energéticos, sea biomasa sólida, biogás o biocombustibles. El potencial de biomasa incluye, entre otras fuentes, los residuos agrícolas, los residuos de la industria forestal y el manejo del bosque nativo. Por su parte, el potencial de biogás se eleva a unos $400 \mathrm{MW}$, parte de los cuales corresponden a la producción de biogás basado en un relleno sanitario.

Al revisar el estado y proyección de la implementación de distintos tipos de energías renovables en el país, es evidente que existen focos que permitirían potenciar la industria como un sector relevante. Nuestro país tiene importantes ventajas competitivas tanto en términos de capital humano como de recursos naturales, debido por ejemplo, a que tiene uno de los niveles más altos del mundo en materia de radiación solar directa, a que cuenta con una potencia de energía marina que no se compara con la de ningún otro lugar, y a las grandes bondades que ofrece el Cordón de Fuego del Pacífico en lo que respecta a geotermia. La utilización de energías renovables no es solo cuestión de regular sus precios sino un problema que involucra numerosas variables: éticas, técnicas, empresariales, muchas veces de financiamiento y en especial la falta de conocimiento. Una política energética mirada más a largo plazo necesariamente debe considerar aspectos como los asentamientos humanos, el ámbito y la planificación territorial, la desconcentración de las fuentes de suministro, la participación de la ciudadanía no solo como actor que interviene en la validación de los proyectos sino en su desarrollo, y, obviamente, el otorgamiento de trato especial a los distintos tipos de tecnología.

La evaluación de los proyectos no puede reducirse a una comparación de costos a nivel de desarrollo, puesto que hay muchos factores ocultos que es preciso considerar y que no se internalizan mediante dicha comparación. A modo de ejemplo, los costos de un proyecto basado en energías renovables hacen que tal vez no sea una solución viable para proveer un bloque de energía de 200 megas, pero en menor escala ese mismo sistema puede perfectamente constituir una solución para una 
empresa agrícola como Subsole, que lo puede incorporar para reemplazar una parte importante de su consumo de energía, con un nivel de ahorro que le permita solventar o adaptar su convertibilidad. Al respecto, el Centro está abocado a estimular y acompañar el desarrollo de proyectos y a afinar la información, tanto en aquellas tecnologías actualmente competitivas, como en las que no lo son, porque entendemos que cada una de ellas tiene un modelo diferente para aproximarse a su despliegue comercial. Hay distintas fuerzas que inciden en que estas tecnologías se acerquen al mercado, y en eso hay que trabajar. Por un lado, están los incentivos de mercado, que consisten básicamente en la ley 20.257; por el otro, está el fomento del desarrollo de la tecnología, esto es, facilitar que haya nuevas soluciones tecnológicas. A respecto, si bien nuestro país mayoritariamente importa y adapta tecnología, existe un proceso de innovación muy potente con tradición e historia, como el que constituyen CONICYT, CORFO, INNO$\mathrm{VA}$, etc. Además, es fundamental que las organizaciones sean claras; se necesita crear un entorno favorable a la inversión y entregar muy buena información a los inversionistas para sensibilizar a la banca respecto de este tipo de inversiones. Finalmente, cabe mencionar recursos y capacidades locales, vale decir, que las condiciones de la infraestructura sean favorables; que haya suficiente capital humano especializado, compañías capaces de hacer ingenierías de perfil competitivas y a precios atractivos para nuevos emprendedores, etc. Todos estos elementos determinan el grado de aproximación de la tecnología al despliegue comercial y no solo el costo de esta que, por lo demás, es un atributo bastante dinámico. Entonces, cada tecnología y cada recurso requieren una reacción especial.

En lo que respecta a las tecnologías que se encuentran cerca del despliegue comercial el Centro realiza un trabajo muy potente en acompañamiento de inversiones, ayudando a superar barreras relacionadas con la distribución, tratando de hacer más objetiva la comercialización de los proyectos y entregando información a los inversionistas respecto de los recursos naturales disponibles, ya que en esta materia todavía subsisten muchos mitos. La etapa de comercialización aún plantea ciertos riesgos tecnológicos, pero sobre todo riesgos de mercado, por lo que el Centro 
está intentando impulsar proyectos demostrativos. Asimismo, contempla préstamos, asistencia y acompañamiento durante el desarrollo de los proyectos para que puedan conseguir el financiamiento y los permisos necesarios y así materializarse en menos tiempo. Finalmente, en la etapa de elaboración de proyectos, el Centro está centrando la atención en las regiones, donde hay un potencial importante de recursos financieros de inversión pública contenido en distintos fondos regionales y carecen de capacidad suficiente para captar proyectos. El gobierno dispone hoy día de un fondo de 85 millones de dólares para proyectos piloto, que a nuestro juicio darán impulso a la adaptación tecnológica. Si bien las iniciativas son mínimas en la medida en que no significan impactos significativos en la matriz, este tipo de proyectos es muy importante en lo relacionado con la generación de conocimiento y la solución de aspectos técnicos. Para terminar, en general la institucionalidad y la ley están funcionando bien y probablemente muchas de las conclusiones que modeló la CADE podrán cumplirse. Se está adelantando o acelerando la utilización de este tipo de tecnologías y ello justifica aún más no solo la inversión en energías competitivas sino también en aquellas que hoy día no lo son. El Centro está elaborando una estrategia más ambiciosa, proponiendo insumos políticos e incentivos que pueden generar efectos más atractivos en el mercado.

\section{VIVIANNE BLANLOT SOZA}

(Ex Ministra de Energía, Directora de Colbun)

Habría que comenzar por decir que los objetivos del desarrollo eléctrico del país son alcanzar un óptimo social basado en la sustentabilidad ambiental y en un abastecimiento adecuado al grado de desarrollo y a los niveles de bienestar deseados por 
la sociedad. Para alcanzarlos, los precios y los costos deben ser competitivos y socialmente sostenibles.

Dicho esto y situándose en el marco de la necesidad de ampliar la matriz eléctrica para satisfacer los crecientes requerimientos de una economía en desarrollo, hay que evaluar el efecto de diversas políticas a partir de escenarios posibles y del potencial que ofrecen las fuentes alternativas. En nuestro país esta labor es realizada por la Comisión Asesora para el Desarrollo Eléctrico (CADE) mediante simulaciones que prevén un descenso de la demanda en el Sistema Interconectado Central (SIC) de $5.5 \%$ a $4.5 \%$ anual entre 2012 y 2030 y un incremento de esta de $3.5 \%$ a $4.7 \%$ anual en el Sistema Interconectado del Norte Grande (SING). El escenario base comprende las políticas que se aplican actualmente y se contemplan diferentes escenarios con políticas alternativas y restricciones. Las simulaciones realizadas muestran matrices posibles y tradeoffs que deben considerarse al definir las políticas.

Las conclusiones de las simulaciones relativas a las posibilidades de desarrollo de la matriz eléctrica muestran que en el SIC las tecnologías de menor costo y mayor competitividad son las de generación hidráulica de gran escala, la geotermia y las minicentrales hidráulicas. Se comprobó que según la tasa de penetración de las energías renovables no convencionales (ERNC), limitar el desarrollo de grandes proyectos hidroeléctricos aumenta el costo entre un $7 \%$ y un $7.5 \%$ y las emisiones de $\mathrm{CO} 2$ entre $37 \%$ y $39 \%$.

En el caso del SIC, para ampliar la matriz eléctrica a partir de energías convencionales sin llevar a cabo proyectos hidroeléctricos de gran escala sería preciso incorporar 3.300 MW de energía nuclear y $3.200 \mathrm{MW}$ producidos por centrales térmicas. De no materializar las centrales de Aysen habría que sustituirlas por $2.600 \mathrm{MW}$ producidos por centrales térmicas. Las emisiones se elevarían un $30 \%$ y el mayor costo actualizado al año de entrada de la primera central de Aysen sería de 2.600 millones de dólares.

En el marco regulatorio actual, el SIC muestra buenas posibilidades de uso de ERNC competitivas, cuya utilización se elevaría a $24 \%$ en 2024 . Sin embargo, hay que tener presente que la incorporación en la matriz de este tipo de energía 
significaría un aumento del precio de la energía eléctrica para todos los consumidores.

La ampliación de la matriz eléctrica del SING en caso de demanda baja se centraría en la tecnología geotérmica, eólica y diesel, previéndose la utilización de un $20 \%$ de ERNC entre 2028 y 2029. Si la demanda es alta, se mantendría el uso de energía geotérmica y el resto se cubriría con carbón y energía nuclear. La tasa de utilización de ERNC en 2030 sería de $12 \%$, a lo que cabe agregar que la imposición de cuotas de participación de esta clase de energía en la matriz implicaría un costo adicional de 453 millones de dólares.

Siempre dentro del tema de las posibilidades de desarrollo de la matriz eléctrica, cabe referirse a la interconexión de los sistemas SIC y SING. Al respecto, su expansión conjunta sin limitaciones de la capacidad de conexión podrían reducir los costos un $4.1 \%$ y podrían ahorrarse anualmente 3384 ton. en emisiones de CO2. Dicha expansión conjunta de ambos sistemas permite una Reserva de Potencia Firme en el SING y una disminución en el SIC. En todo caso, la interconexión podría redundar en un beneficio de 1600 millones de dólares actualizado al año de entrada en operación del proyecto, monto del cual habría que descontar el costo de la línea de interconexión.

En el plano internacional, los procesos de interconexión e integración regionales tardan en madurar y requieren acuerdos políticos firmes y estables. Exigen conciliar regulaciones operacionales y económicas, así como sistemas eficaces de solución de conflictos que sean efectivos. En cuanto a la integración regional, ahora mismo podrían iniciarse los procesos de negociación pertinentes y en circunstancias políticas favorables cabría prever una integración que abarque Colombia, Ecuador, Perú y Chile dentro de unos 8 a 10 años. No hay que dejar de lado la posibilidad de integración con Paraguay, país con el cual no hay conflictos políticos.

En lo que respecta a las energías renovables no convencionales (ERNC), Chile tiene un potencial competitivo que puede penetrar a tasas importantes, incluso sin cambios regulatorios. La energía hidroeléctrica, incluyendo las grandes centrales y las minicentrales en calidad de ERNC, es esencial para la matriz eléctrica futura. La energía del sur tiene alto valor 
estratégico y beneficios importantes en materia de costos y emisiones de gases de efecto invernadero. La energía nuclear aparece como solución hacia mediados del próximo decenio y hay que mantener el proceso en estudio para poder tomar decisiones cuando llegue el momento.

El conflicto ambiental y territorial constituye un desafío para el desarrollo eléctrico, por lo cual hay que estudiar cómo lograr un uso adecuado de las fuentes más competitivas en armonía con el medio ambiente y la sociedad y cómo lograr una mayor aceptabilidad social del desarrollo eléctrico. Estos aspectos fueron examinados por la CADE a fin de elaborar estrategias para mejorar los estándares ambientales y lograr la aceptación social del desarrollo eléctrico.

Visto lo anterior se estudiaron diversas propuestas. En lo que se refiere al ordenamiento territorial y en relación con las centrales termoeléctricas se puso énfasis en la necesidad de definir las áreas vetadas a estas centrales y las zonas especialmente aptas. Se propuso estudiar la posibilidad de venta de bienes nacionales, el otorgamiento de concesiones en esta clase de bienes y la definición de líneas de base por parte del Estado. Como alternativa, se propuso que los proyectos térmicos en esas zonas determinadas sean desarrollados y preaprobados, de manera de proceder después a licitarlos y concesionarlos.

Para mejorar los estándares ambientales, las propuestas se centraron en la protección de la salud, el cambio climático, la conservación de los recursos naturales y la biodiversidad, y la Evaluación Ambiental Estratégica. En el primer caso se propuso crear una red de monitoreo en línea de la calidad del aire que el ciudadano pueda comprender, así como mejorar los modelos de dispersión de los contaminantes y el conocimiento de sus efectos. En materia de cambio climático, se hizo hincapié en la necesidad de definir claramente las metas de reducción de los gases de efecto invernadero (GEI), en apoyar la iniciativa MAPS (MAPS-Chile: opciones de mitigación para enfrentar el cambio climático), y en limitar el incremento de los GEI aplicando medidas eficaces en función del costo que conduzcan a cambios en el comportamiento en las técnicas y los sistemas de producción.

La conservación de los recursos naturales y la biodiversidad requiere aplicar una política de localización de las centrales tér- 
micas, proteger los tramos de los cursos de agua de acuerdo con su valor ecológico y elaborar una guía de evaluación del caudal ambiental en el marco del Servicio de Evaluación Ambiental (SEA), consensuada a nivel interministerial. Debe exigirse la revisión del Caudal Ecológico Mínimo en un período que podría ser de 30 a 50 años. Asimismo, habría que desarrollar nuevos convenios de operación de las centrales existentes, incorporando la dimensión ambiental y crear un sistema de información ambiental con indicadores ambientales de las centrales generadoras existentes, de acuerdo con un modelo acordado entre el Ministerio del Medio Ambiente y el sector privado.

Una medida importante para mejorar los estándares ambientales es establecer la práctica de realizar la Evaluación Ambiental Estratégica (EAE) de la política eléctrica, para lo cual habría que impulsar el desarrollo de metodologías y su aplicación a partir de una fecha determinada.

Con el apoyo de especialistas de las ciencias sociales y de las comunicaciones la CADE analizó la creciente oposición a las inversiones en el sector eléctrico de grupos de la ciudadanía. La idea fue comprender la causa del fenómeno y sacar enseñanzas que permitan conciliar el desarrollo eléctrico y las prioridades de la ciudadanía.

En la sociedad hay una demanda creciente de mayor acceso a la información y a la participación en la discusión sobre las políticas públicas. Por su parte, han aumentado las exigencias de transparencia y "accountability» de las instituciones encargadas de las políticas ante el deterioro de la credibilidad de las instituciones encargadas de las decisiones clave de la política pública. Se observan riesgos para el avance en las políticas críticas para el desarrollo económico y social por lo cual es fundamental comprender la formación de percepciones y abrir mayores espacios de información y diálogo, aumentar y mejorar la participación y desarrollar capacidades para construir acuerdos y manejar los conflictos.

Para hacer frente a los problemas anteriores y mejorar las instancias de información y de participación a nivel local y de proyectos específicos, es preciso estimular la participación en la evaluación ambiental de los planes reguladores, crear espacios participativos para cada etapa de la Evaluación del Impacto Ambiental (EIA) y ampliar los mecanismos de 
participación contemplando metodologías deliberativas, proyectuales y métricas.

A nivel nacional se propone instaurar una sistema participativo de discusión de la política energética de largo plazo que contemple convocatoria periódica a un análisis de esta por las autoridades de medio ambiente y energía, el examen de los principales temas en discusión en la sociedad en materia de políticas de largo plazo, convocatoria y participación amplia, y la elaboración de un informe integrado que aborde las opiniones recogidas y la propuesta de política de largo plazo presentada en el Congreso.

\section{RENE MUGA}

(Gerente General de la Asociación de Generadoras)

\section{Los DESAFíos DE LA ENERGía ELÉCTRICA EN CHILE}

Nuestro país ha crecido en las últimas décadas, aumentando el bienestar y mejorando la calidad de vida de sus habitantes. Este progreso lleva aparejado un aumento del consumo de electricidad cercano a la tasa de crecimiento del producto interno bruto. La demanda de energía se ha duplicado cada 10 a 12 años, fenómeno que se repetirá en las próximas décadas en la medida en que el país mantenga su dinamismo. El consumo anual per cápita de energía eléctrica en Chile es menos de la tercera parte del promedio de la OCDE, lo que demuestra que existe amplio margen para que siga creciendo.

Al mismo tiempo, como lo revela la experiencia de los países desarrollados, el mejoramiento de la calidad de vida y el mayor consumo de electricidad están íntimamente vinculados. El avance tecnológico y productivo, así como 
los principales aspectos de la vida moderna implican una creciente demanda de energía eléctrica.

Debido a lo anterior, uno de los desafíos más importantes que Chile tiene por delante es responder adecuadamente a ese aumento de la demanda mediante un desarrollo de la generación y de la transmisión que acompañe ese crecimiento y se sostenga, a la vez, en tres principios básicos: confiabilidad o seguridad de suministro, competitividad y sustentabilidad ambiental y social.

La industria de la generación ha conocido desafíos. La crisis de suministro de gas desde Argentina se enfrentó con responsabilidad y rapidez. Es así como del 2006 a la fecha se han puesto en marcha proyectos por más de $5.000 \mathrm{MW}$ (un tercio de toda la capacidad instalada en Chile). Sin embargo, para hacer frente a este nuevo y mucho más importante reto de pasar de los actuales 17 mil MW a unos 40 mil MW de capacidad instalada en 20 años se requiere un gran esfuerzo de todos los actores.

Desarrollar proyectos de generación en el país se ha tornado mucho más complejo debido a una serie de razones. Entre ellas cabe mencionar los atrasos en la tramitación de los proyectos, los plazos cada vez mayores que se requieren para obtener concesiones eléctricas y servidumbres, las dificultades con que se tropieza en la relación con las comunidades, la judicialización de los proyectos y el atraso en las obras conexas (por ejemplo, de transmisión).

El gobierno ha tomado nota de estas crecientes dificultades. Es así como el año recién pasado se convocó a un destacado grupo de expertos que conformaron la Comisión Asesora para el Desarrollo Eléctrico (CADE) cuyo informe, así como el de otras iniciativas, constituyeron insumos muy relevantes para la Estrategia Nacional de Energía presentada a fines de febrero pasado, carta de navegación que contribuye a fijar metas y criterios centrales para el desarrollo energético del país. A partir de este documento, debieran surgir propuestas concretas y definirse las prioridades que ayuden a avanzar en el desarrollo de la capacidad de generación y transmisión que el país requiere.

En las últimas semanas, el desafío energético y las dificultades para llevar adelante proyectos ha vuelto a estar muy presente en el debate público. 
La autoridad acaba de presentar al Congreso un proyecto de ley que pretende agilizar la tramitación de concesiones y servidumbres. A esta iniciativa debiera agregarse próximamente un proyecto que proponga una estructura concreta para definir el concepto de Carretera Eléctrica y permita ampliar el sistema de transmisión, con una mirada de más largo plazo. De esta manera se podría conectar nuevos proyectos a una red más robusta que evitara congestiones y cuellos de botella.

Ambas iniciativas, que son complementarias, generarán sin duda una discusión que involucrará a muchos actores y que ojalá permita avanzar con rapidez en su análisis y definición, sin perder de vista el gran desafío que enfrenta el país.

A las iniciativas anteriores deben sumarse otras, tanto en el plano legal como reglamentario, destinadas a poner en ejecución las prioridades contenidas en la mencionada Estrategia Nacional de Energía. A ello debiera agregarse un rol activo de la autoridad para desarrollar los contenidos más urgentes y relevantes de la Estrategia, encausando el debate y aportando una visión de largo plazo que es fundamental.

Pese a los esfuerzos realizados, el incremento de la oferta de generación eléctrica enfrenta grandes incertidumbres y obstáculos que hacen cada vez más difícil poder avanzar al ritmo de la demanda. Esto debe corregirse a fin de evitar estrecheces y perjudicar la seguridad, competitividad y sustentabilidad del suministro eléctrico a mediano plazo.

Crear un clima de menor incertidumbre y eliminar obstáculos no son tareas fáciles; en general, son procesos que toman tiempo e involucran la participación de muchos actores. La tarea puede facilitarse si avanzamos en la creación de un espacio de confianza y diálogo con las comunidades, fortaleciendo las condiciones que permitan abordar y resolver las preocupaciones y las inquietudes de distintos grupos sociales respecto de los proyectos de generación eléctrica.

Las demoras en la aprobación de los proyectos de generación y transmisión así como en su construcción, tienen un alto costo para el país y a mediano plazo (2016-2017) pueden generar estrechez en la oferta de energía eléctrica. Asimismo, a corto plazo inciden en el alto costo marginal, particularmente si los precios de los combustibles siguen siendo elevados y las condiciones hidrológicas son desfavorables. 
Otro aspecto que genera incertidumbre es la forma en que finalmente se decida la incorporación de las denominadas ERNC. Estas se ven favorecidas por la ley 20.257 que obliga a inyectar al sistema una proporción creciente de los retiros que se efectúan para abastecer los contratos de energía. Este porcentaje es actualmente de $5 \%$ y se elevará anualmente hasta llegar a $10 \%$ en 2024 .

Las tecnologías de las fuentes de energía renovables no convencionales están aumentando continuamente su competitividad. Como lo indica la creciente participación de estas tecnologías en el sistema de aprobación ambiental de los proyectos, ello permitirá que estas fuentes sigan incorporándose en la matriz. Casi un tercio de los proyectos eléctricos aprobados que aún no comienzan a construirse lo constituyen tecnologías definidas por la ley como ERNC. Esta proporción supera el $40 \%$ cuando se consideran los proyectos que aún se encuentran en trámite de aprobación ambiental.

Si a ello se agrega la generación hidráulica en condiciones hidrológicas normales, Chile posee una de las matrices de generación más renovables del mundo, con cerca de la mitad de la producción total.

Sin embargo, es importante comprender que al igual que los demás proyectos eléctricos, los de ERNC enfrentan el mismo escenario complejo de tramitación y desarrollo que afecta a todos los tipos de generación. Además, en muchos casos deben superar el desafío de una adecuada conexión con los sistemas de transmisión y mantener estabilidad de suministro y seguridad de respaldos.

Chile debe seguir su camino hacia el desarrollo social y económico para lo cual es esencial el abastecimiento de energía eléctrica suficiente, competitiva y sustentable. Difícilmente podrá avanzarse a menos que todos los actores involucrados, tanto autoridades como la industria y la comunidad, encuentren espacios para lograr los mayores acuerdos posibles, con mirada de largo plazo, actitud constructiva y privilegiando el desarrollo seguro de nuestro sistema eléctrico.

En lo que nos compete como industria de generación, hace un año se creó la Asociación Gremial de Generadoras, precisamente para complementar su esfuerzo productivo en el desarrollo de sus inversiones y contribuir a cimentar una 
discusión constructiva e informada sobre la generación y su composición mediante un diálogo objetivo y el aporte al diseño de políticas sectoriales.

De esta manera, la industria de la generación eléctrica puede seguir avanzando en la diversificación de las fuentes de generación, aprovechando de manera competitiva todo el potencial de fuentes renovables de que dispone el país, como complemento de la necesaria energía de base hídrica y térmica, sujetas a las más estrictas normas ambientales y de emisiones como las que Chile aplica desde el año 2011.

La industria de la generación eléctrica está disponible para contribuir a aumentar los esfuerzos que promueve la autoridad para desarrollar políticas eficaces de eficiencia energética e introducir nuevas tecnologías de redes inteligentes. 